\title{
Photoelectrodes with Polydopamine Thin Films Incorporating a Bacterial Photoenzyme
}

\section{Marco Lo Presti, Maria Michela Giangregorio, Roberta Ragni, Livia Giotta,} Maria Rachele Guascito, Roberto Comparelli, Elisabetta Fanizza, Roberto R. Tangorra, Angela Agostiano, Maria Losurdo, Gianluca M. Farinola,* Francesco Milano,* and

\section{Massimo Trotta*}

A fabrication strategy of photoactive biohybrid electrodes based on the immobilization of the bacterial reaction center (RC) onto indium tin oxide (ITO) is proposed. The RC is an integral photoenzyme that converts photons into stable charge-separated states with a quantum yield close to one. The photogenerated electron-hole pair can be eventually exploited, with suitable redox mediators, to produce photocurrents. To this purpose, RC must be effectively anchored on the electrode surface and simple strategies for its stable immobilization ensuring prolonged enzyme photoactivity are strongly desired. In this work, polydopamine (PDA), a polymer reminiscent of the natural melanin, is used to anchor the RC on the electrode surface. PDA is easily prepared in situ by spontaneous polymerization of dopamine in slightly alkaline aerated buffered RC solution. This reaction, carried out in the presence of an ITO substrate dipped into the solution, directly leads to a stable RC-PDA/ ITO photoelectrode with $20 \mathrm{~nm}$ film thickness and $50 \%$ of fully functional RC occupancy. Photocurrents densities recorded using this photoelectrode are comparable to those obtained with far more sophisticated immobilization techniques. The RC-PDA films are fully characterized by visible-near-infrared absorption spectroscopy, ellipsometry, atomic force, and scanning electron microscopies.

\section{Introduction}

Biohybrid assemblies exploiting the 17 unmatched ability of the photosynthetic 18 proteins to convert solar light into charge 19 separated states are arousing great atten- 20 tion as highly efficient, biocompatible, and 21 eco-sustainable optoelectronic devices. ${ }^{[1-3]} \quad 22$

In plants, algae and cyanobacteria, 23 the complex apparatus formed by two 24 photosynthetic units, the photosystems 25 one and two (PSI and PSII), efficiently 26 exploit solar energy to oxidize water into 27 molecular oxygen transferring electrons 28 to the nicotinamide adenine dinucleo- 29 tide. ${ }^{[4,5]}$ The use of PSI and PSII as pho- 30 toactive biocomponents in optoelectronic 31 devices is a hot topic of current scientific 32 research ${ }^{[6]}$ although some issues related 33 to the PSII stability have been reported. 34 On the other side, bacterial reaction 35 centers (RC), homologous to the photo- 36 chemical core of the PSII, obtained from 37 the purple photosynthetic bacteria Rho- 38 dobacter $(R$.) sphaeroides have also raised 39 interest for similar applications. Bacterial 40

Dr. M. Lo Presti, Dr. R. Ragni, Prof. E. Fanizza, Dr. R. R. Tangorra,

Prof. A. Agostiano, Prof. G. M. Farinola

Chemistry Department

University of Bari "Aldo Moro"

via Orabona 4, Bari I-70126, Italy

E-mail: francesco.milano@cnr.it

Dr. M. M. Giangregorio, Dr. M. Losurdo

CNR NANOTEC

UOS Bari

via Orabona 4, Bari 1-70126, Italy

Dr. L. Giotta, Prof. M. R. Guascito

Department of Biological and Environmental Sciences and Technologies University of Salento

sp Lecce-Monteroni, Lecce I-73100, Italy

Dr. R. Comparelli, Dr. F. Milano, Dr. Massimo Trotta

CNR IPCF

UOS Bari, via Orabona 4, Bari I-70126, Italy

E-mail: massimo.trotta@cnr.it; gianlucamaria.farinola@uniba.it

The ORCID identification number(s) for the author(s) of this article can be found under https://doi.org/10.1002/aelm.202000140.

DOI: 10.1002/aelm.202000140
RCs are indeed easy to isolate and purify, are sturdy proteins 41 and can be handled outside its native environment without 42 loss of functionality. ${ }^{[7,8]}$ Furthermore, mutants of $R$. sphaeroides 43 can be easily engineered for introducing new and intriguing 44 features. ${ }^{[9]}$

The RC isolated from the mutant R26 of the phototropic 46 bacterium $R$. sphaeroides, is a transmembrane pigment-protein 47 complex (Figure 1) consisting of three subunits (H, L, and M) 48 forming a protein scaffold to which nine cofactors are nonco- 49 valently bound in precise positions: two ubiquinone-10 $\mathrm{Q}_{\mathrm{A}}$ and 50 $\mathrm{Q}_{\mathrm{B}}$, a nonheme $\mathrm{Fe}^{2+}$ ion, two bacteriopheophytins (BPhe) and 51 four bacteriochlorophylls (BChl), two of which form a func- 52 tional dimer (D). ${ }^{[10,11]}$ Upon photon absorption, one electron 53 moves from $\mathrm{D}$ to the first electron acceptor $\mathrm{Q}_{\mathrm{A}}$ and finally to 54 the loosely bound $\mathrm{Q}_{\mathrm{B}}$, generating an electron-hole couple with 55 unitary quantum yield. ${ }^{[12]}$ In the absence of external reductants, 56 a charge recombination reaction occurs in a timescale from 0.157 up to few seconds. Conversely, in the presence of exogenous 58 electron donor to the oxidized dimer (e.g., the physiological 59 

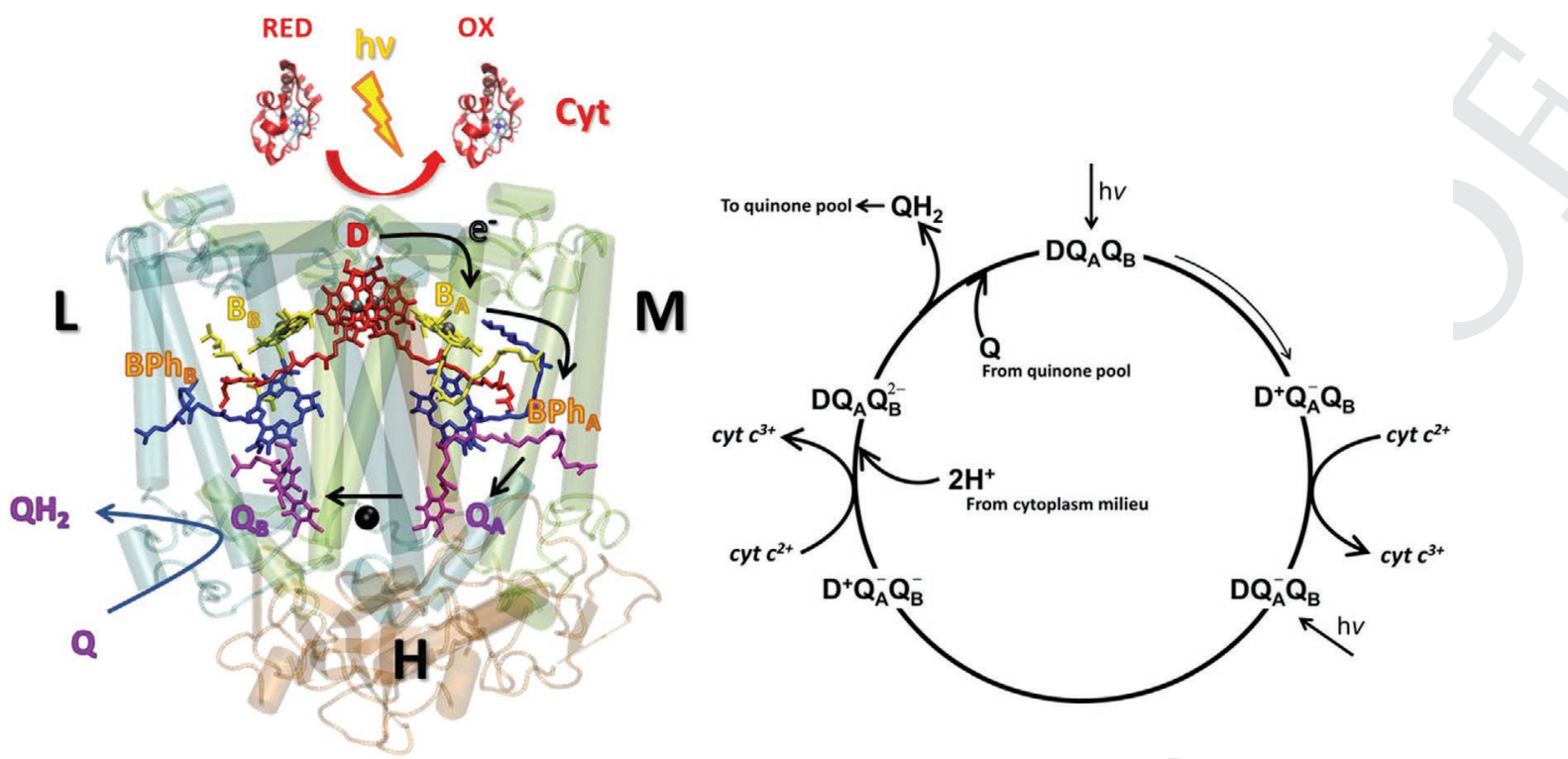

Figure 1. 3D structure of the photosynthetic reaction center from the mutant R26 of the bacterium R. sphaeroides (Protein data bank ID code: 2J8C[13]). In transparence is represented the protein scaffolding where the alfa helixes are shown as cylinders. The RCs has an elliptical transmembrane region having $5 \times 7 \mathrm{~nm}$ main axes, capped with a hemispheric globular portion having a radius of $3.5 \mathrm{~nm}$. In plain colors are shown the cofactors involved in the cascade of electron transfer reactions originating from the photoexcitation of the bacteriochlorophyll dimer (D, in red). Other cofactors are two monomeric bacteriochlorophylls ( $\mathrm{BChl}$, in yellow), two bacteriopheophytins $(\mathrm{H}$, in blue), two quinones $(\mathrm{Q}$, in mauve), and one ferrous ion (in black) arranged in two branches identified by the subscripts $A$ and $B$. The cofactors span across the subunits $L$ and $M$ (in pale green and cyan) that sit within the membrane, while the third subunit $\mathrm{H}$ (in pale orange) protrudes toward the cytoplasm of the bacterial cell. The black arrows represent the forward electron transfer reactions from $D$ to $Q_{B}$ that take place only through the branch $A$, the red arrow represents the electron transfer from the exogenous donor, in this case a cytochrome (Cyt), to the oxidized dimer. The blue arrows represents the quinone/quinol exchange reaction at the $\mathrm{Q}_{\mathrm{B}}$ binding site. ${ }^{[14-16]}$ B) The cyclic electron-transfer from ferrocytochrome to quinone sustained by light and mediated by exogenous pools of electron donors and acceptors. ${ }^{[10]}$

cytochrome $\mathrm{c}_{2}$ ), a second electron can be shuttled to $\mathrm{Q}_{\mathrm{B}}$ that, upon double protonation, is released as quinol and can be substituted by a quinone from a pool in the external medium (Figure 1).

The photocycle can be reproduced using isolated RC suspended in direct, ${ }^{[7,17]}$ or inverse micellar systems, ${ }^{[18]}$ in biomimetic environments, such as liposomes ${ }^{[19-21]}$ and giant vesicles, $^{[22]}$ or in nonaqueous media (e.g., deep eutectic solvents). ${ }^{[23,24]}$

To exploit the RC photoconversion efficiency, its application in photoelectrochemical systems requires a suitable immobilization strategy ensuring both protein integrity and efficient electron transfer from the protein to the surface of an electrode.

Various approaches have been recently reviewed ${ }^{[1,25]}$ and include: 1) layer-by-layer electrostatic adsorption of negatively charged RC onto polycationic modified electrodes; ${ }^{[26]} 2$ ) entrapment by physisorption of the protein in nanoporous materials $^{[27,28]}$ and sol-gel media ${ }^{[26]}$ or directly onto the electrode via laser printing ${ }^{[29]}$ or Langmuir-Blodgett techniques; ${ }^{[30,31]} 3$ ) covalent binding the RC to the electrode surface by suitable protein linkers or polyhistidine (polyHis) tag at the C-terminal of $\mathrm{M}$ subunit of genetically engineered $\mathrm{RC}^{\left[{ }^{[32]}\right.}{ }^{4}$ ) casting a layer of oxidized cyt onto an indium tin oxide (ITO) Gate, prior to RC deposition, to induce an orientation of the photoenzyme that enabled the construction of a novel Light-driven electrolytegated organic transistor. ${ }^{[33]}$

An alternative attaching strategy based on the adhesive properties of polydopamine (PDA) uses a straightforward one-pot molecule encapsulation to produce firmly anchored films on the surface of a dipped electrode in aqueous aerated buffered solution. Dopamine (3,4-dihydroxyphenethylamine, DA) easily polymerizes in presence of oxidant in alkaline aqueous solutions, ${ }^{[34-39]}$ forming a robust melanin-like underwater adhesive polymer, ${ }^{[40]}$ the PDA, composed of 5,6-dihydroxy-indole repeating units and its derivatives. ${ }^{[34]} \mathrm{PDA}$ is a promising active material for bioelectronic platforms due to 1) its high biocompatibility and mild $\mathrm{pH}$ and temperature polymerization conditions highly compatible with biomolecules, ${ }^{[41]}$ 2) strong adhesion ability, even in wet conditions, to a wide variety of substrates forming robust films without the need of surface pretreatment, ${ }^{[42]} 3$ ) efficient semiconducting properties, ${ }^{[43-47]} 4$ ) potential covalent functionalization of PDA films by chemical reactions of catechol moiety on the surface groups of PDA. ${ }^{[38,48]}$

PDA has been already used as efficient adhesive biocompatible polymer for immobilization or encapsulation of enzymes (e.g., laccase, ${ }^{[49]}$ glucosidase, ${ }^{[50]}$ peroxidase ${ }^{[51]}$ ) leading to promising biohybrid materials for catalysis, drug delivery, and biosensing.

We present here a simple and reliable wet procedure for the assembly of photoactive RC-PDA/ITO electrodes prepared by mixing aqueous RC and DA solutions in the presence of ITO under aerobic and slightly alkaline conditions. RC effectively encapsulates during the polymerization step, and the PDA adhesion property drives the simultaneous immobilization onto the electrode surface. The encapsulated protein retains full structural integrity and photochemical capability. The RC-PDA/ITO electrode was tested in a photoelectrochemical 
cell in the presence of ferrocenemethanol as exogenous electron donor and decylubiquinone as electron acceptor. Photocurrents densities (up to $20 \mu \mathrm{A} \mathrm{cm} \mathrm{cm}^{-2}$ ) and internal quantum efficiency (up to 38\%) are comparable to those obtained with more sophisticated immobilization techniques. ${ }^{[31,52]}$ Interestingly, the electrochemical mediators can be coincorporated within the PDA matrix together with the protein, enabling the device functioning with lower but more stable photocurrents, adding the sole ferrocyanide as electroactive species in the electrolytic solution. The RC-PDA films of the electrode were characterized by steady state and time resolved vis-NIR absorbance spectroscopy, ellipsometry, atomic force microscopy (AFM), and scanning electron microscopies (SEM).

\section{Results and Discussion}

The polymerization of dopamine into PDA in presence of the $\mathrm{RC}$ is graphically sketched Figure 2a. Under the conditions illustrated in this work, DA molecules are initially oxidized by oxygen forming a series of intermediates that eventually lead to the formation of PDA nanoaggregates which encapsulate the photoenzyme. We imagine the protein, surrounded by its detergent belt, to accommodate within the solution-filled voids (illustrated in Figure S7, Supporting Information) within the growing PDA structures shown by AFM images (see later). The nanoaggregates remain suspended in the buffer solution unless an ITO surface is available during the polymerization. If so, the nanoaggregates coalesce, adhere, and deposit on the ITO surface forming a stable RC-PDA film amenable as photoelectrode.

\subsection{Optimization of the Polymerization Conditions}

Polymerization conditions compatible with the presence of the $\mathrm{RC}$ require a specific aqueous buffer containing a surfactant, here Triton X-100 $0.03 \% \mathrm{v}: \mathrm{v}$, to ensure the solubilization of the membrane protein, and a buffer to maintain the $\mathrm{pH}$ value at 8.0 throughout the reaction. Tris has $\mathrm{p} K_{\mathrm{a}}=8.07$ and buffer capacity $\beta($ Tris, $\mathrm{pH} 8.0)=0.57 \times 10^{-3} \mathrm{M} \mathrm{pH}^{-1}$ and, furthermore, leads to higher polymerization yield then phosphate buffer at this $\mathrm{pH} .{ }^{[54]}$ Unfortunately, Tris is covalently incorporated into the PDA matrix. ${ }^{[5]}$ Phosphate has lower $\mathrm{p} K_{\mathrm{a}}=7.21$ and buffer capacity $\beta$ (phosphate, $\mathrm{pH} 8.0)=0.27 \times 10^{-3} \mathrm{M} \mathrm{pH}^{-1}$ but is not involved in the polymerization process and is hence chosen as alternative buffer. The polymerization reaction, shown in Figure $2 \mathrm{~b}$, releases two protons per DA molecule during the initial oxidation step, ${ }^{[53]}$ hence high $\mathrm{pH}$ buffer concentration, namely $\mathrm{T}_{250} \mathrm{TX}_{0.03}$ and $\mathrm{P}_{250} \mathrm{TX}_{0.03}$, were used. The polymerization of dopamine into PDA in presence of the RC is graphically sketched Figure 2a. The structural differences in the films obtained with Tris and phosphate are discussed in detail in Section 2.3. See the Experimental Section for abbreviations.

\subsection{In Situ PDA Assisted Deposition of RC onto ITO Electrode}

Encapsulation of RCs into PDA nanoaggregates was confirmed by steady state absorption vis-NIR spectroscopy (Figures S1-S3,
Supporting Information), fluorescence reflection microscopy 1 (Figure S4, Supporting Information), and transient absorp- 2 tion NIR spectroscopy (Figure S5, Supporting Information). 3 Adventitious coprecipitation of RC and PDA nanoaggregates is 4 also excluded (Figure S2, Supporting Information) by control 5 experiments.

The initial concentration of dopamine modulates the 7 amount of RCs incorporated in nanoaggregates as well as, see 8 later, the thickness of the final film. A $5 \times 10^{-3} \mathrm{M}$ concentration 9 of DA was selected as best compromise between film thick- 10 ness (see Section S3, Supporting Information) and amount 11 of entrapped RC (Figure 3). Indeed, higher DA concentra- 12 tion increases the entrapment of RC but makes it thicker 13 and darker, limiting the enzyme photoexcitation and electron 14 transfer to the electrode.

The film sketched in Figure 2a forms after overnight stir- 16 ring only if dopamine is allowed to polymerize in presence of 17 the target ITO surface. If ITO is added after the formation of 18 nanoaggregates, no adhesion is obtained. This difference may 19 be a consequence of the higher amount of catechol moieties 20 of the oxidized forms of DA available during the polymeri- 21 zation reaction as compared to those available once nanoag- 22 gregates have formed. ${ }^{[40]}$ Although the mechanism behind 23 the formation of polydopamine is still under debate, litera- 24 ture shows that, under alkaline conditions, dopamine under- 25 goes to a first oxidation of catechol groups into quinones, 26 and then to a complex series of reactions leading to a final 27 polymer with hyperbranched and stacked chemical structure 28 (Figure 2b). ${ }^{[56,57]}$ In the presence of an anchoring surface, 29 such as ITO, the catechol groups of some PDA precursors 30 may be responsible of the adhesion and the consequent film 31 formation, whose final thickness is of the order of tens of 32 nanometers. ${ }^{[56]}$

\subsection{AFM, Ellipsometric, and SEM Surface Characterization of PDA and RC-PDA Films}

The nanoaggregates of PDA, their films, and the effect of RC encapsulation were investigated by AFM, SEM, and ellipsometry under different polymerization conditions. Details are given in Section S6 of the Supporting Information and briefly summarized here.

The average particle diameter of PDA nanoaggregates is found to depend upon the initial DA concentration regardless the buffer used during polymerization. Diameter was found to increase from $\approx 60 \mathrm{~nm}$ (50 in Tris buffer and 70 in phosphate buffer) to $\approx 150 \mathrm{~nm}$. The thickness of the film increases linearly with the DA concentration, passing from 20 to $100 \mathrm{~nm}$ when polymerization occurs in Tris. In the case of polymerization performed in phosphate buffer, the thickness of the PDA film starts at $20 \mathrm{~nm}$, reaches the maximum value of $50 \mathrm{~nm} 52$ at DA $10 \times 10^{-3} \mathrm{M}$ and decreases at higher DA concentrations (see Figure S6, Supporting Information). The size differences 54 between nanoaggregates and film clearly denote different for- 55 mation processes.

The role of RC addition is summarized in Figure 3. Note- 57 worthy, independently on buffer and DA concentration, we 58 measured a 50-60 nm similar size of PDA particles, indicating 59 
(a)
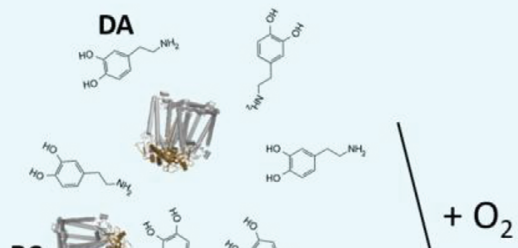

RC

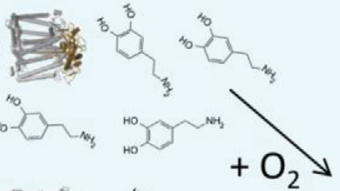<smiles>O=[N+]([O-])O[O-]</smiles>
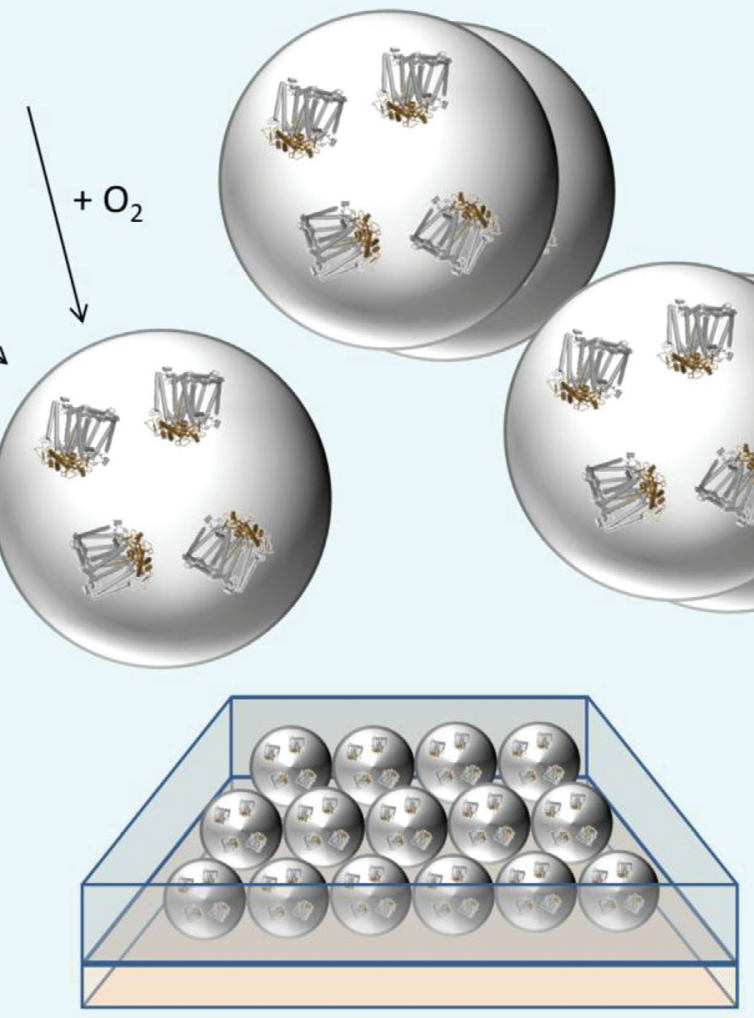

(b)

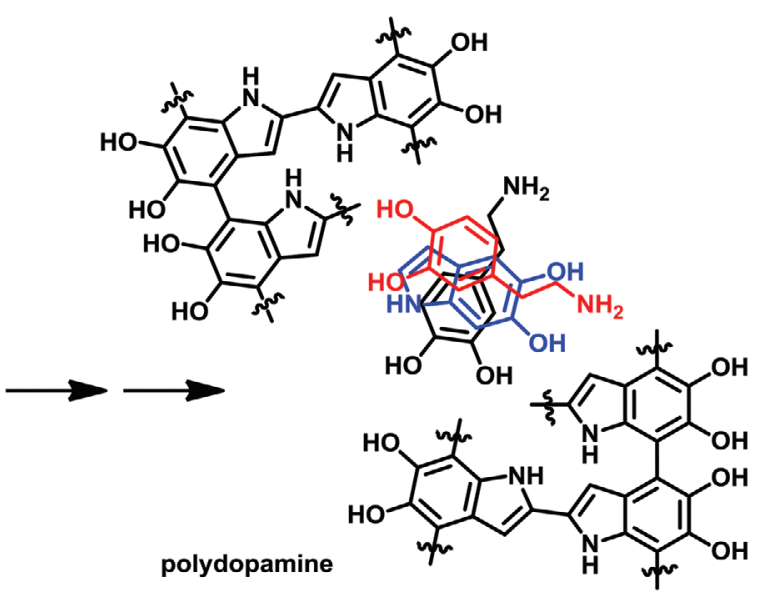

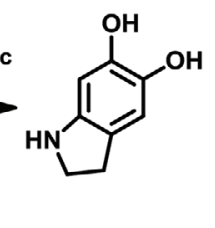

eukodopaminechrome

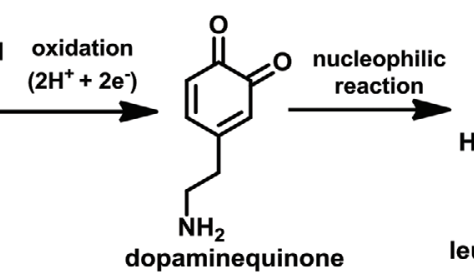

dopaminequinone

Figure 2. a) Schematic representation of the polymerization steps that take place in aqueous solution buffered at $\mathrm{pH} 8.0$ by Tris or phosphate buffer in the presence of the ITO glass. b) Scheme of the reactive intermediates formed during the dopamine polymerization reactions (adapted with permission from Hong et al. $\left.{ }^{[53]}\right)$.

that RC is an inhibitor of PDA particle aggregation. This size is much larger than dimensions of the RC presented in the caption of Figure 1. Furthermore, in phosphate, the RC-PDA film morphology and surface roughness do not significantly change by increasing the PDA concentration and film thickness. Conversely, in Tris, a hierarchical aggregation in films of the particles occurs during deposition with consequent change of morphology and increase of roughness with film thickness, indicating again a role of the Tris also during the $\mathrm{RC}$ encapsulation process. This morphology is consistent with 

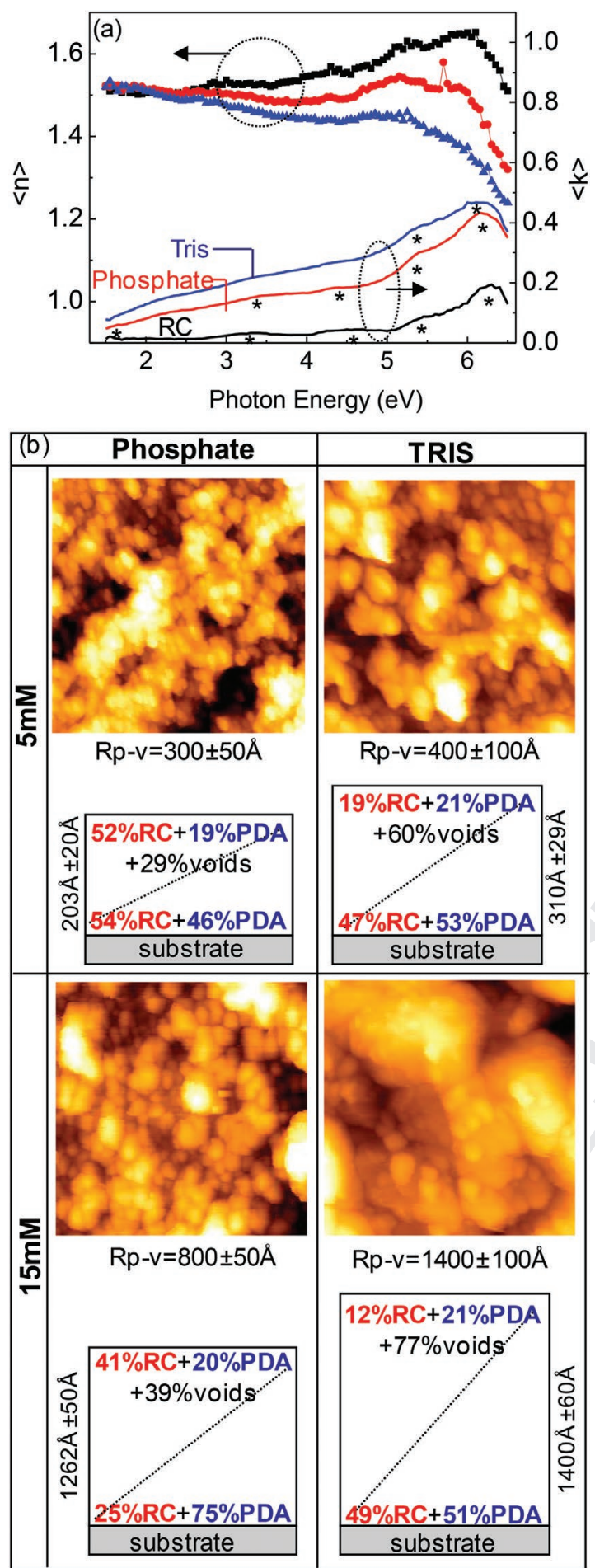

Figure 3. a) Ellipsometric spectra of the pseudorefractive index, $\langle n\rangle$, and pseudoextinction coefficient, $<k>$, of films of RC (black), of RC-PDA from $5 \times 10^{-3} \mathrm{M}$ PDA in phosphate (red) and of RC-PDA film from $5 \times 10^{-3} \mathrm{M}$ PDA in Tris (blue). b) $1 \times 1 \mu \mathrm{m}^{2}$ morphological images and corresponding graded structural models obtained by ellipsometric analysis for RC-PDA films deposited using phosphate and Tris and different DA concentrations $\left(5 \times 10^{-3} \mathrm{M}\right.$ and $\left.\times 10^{-3} \mathrm{M}\right)$. In the ellipsometric models, the film thickness and the composition (\% volume) of the bottom and top of the graded films in terms of volume fractions are shown. Morphological Rp-v values are also reported.

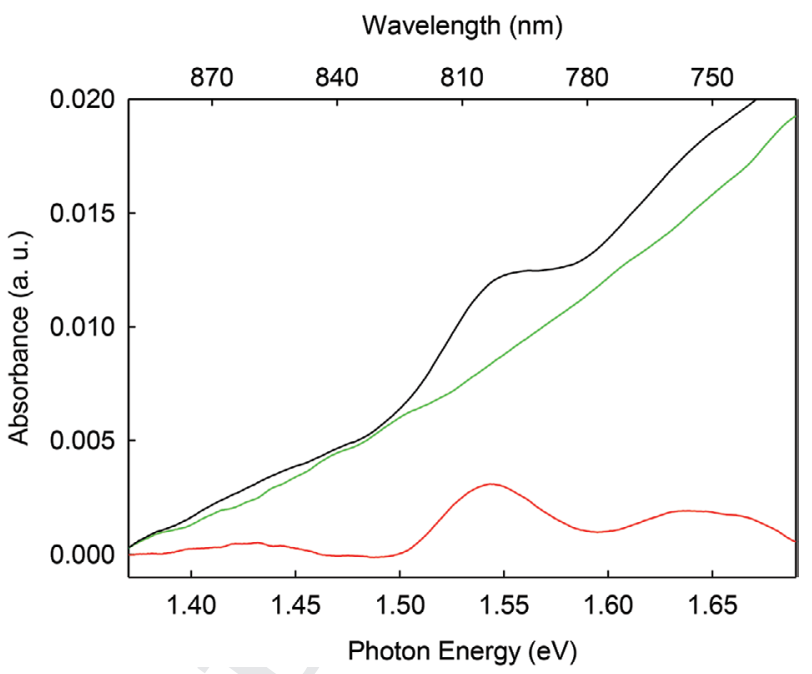

Figure 4. Absorption spectrum of RC-PDA/ITO (black line). Polymerization conditions: $\mathrm{RC} 3 \times 10^{-6} \mathrm{M}$, DA $5 \times 10^{-3} \mathrm{M}$ in $\mathrm{P}_{250} \mathrm{TX}_{0.03}, \mathrm{pH}$ 8.0. The $\mathrm{RC}$ calculated spectrum (red line) is obtained by subtracting the spectrum of the PDA/ITO (green line) from the black line.

the ellipsometric analysis. Specifically, Figure 3a shows ellipso- 24 metric spectra of the pseudorefractive index, $\langle n\rangle$, and extinc- 25 tion coefficient, $\langle k>$, of RC-PDA films obtained from both Tris 26 and phosphate buffers; for comparison, the spectrum of RC 27 alone deposited by drop casting on the substrate is shown. The 28 presence of the RC optical transitions at 1.52, 3.1, 4.3, 5.35, and 29 $6.2 \mathrm{eV}$ (see the Experimental Section) is a clear indication of 30 the RC incorporation in the films (in agreement with vis-NIR 31 spectrum in Figure 4). The modeling and best-fit of the ellipso- 32 metric spectra resulted in a quantitative evaluation of the RC 33 incorporation (\%volume fraction) and thickness of the RC-PDA 34 films. The films have been fitted to a gradient in the three com- 35 ponents RC, PDA, and voids, introduced to simulate the rough- 36 ness of the films.

Thickness and roughness (as indicated by the voids surface 38 $\%$, consistently with AFM measurements in Figure 3b) for the 39 RC-PDA films obtained in Tris are higher with respect to films 40 obtained in phosphate, indicating once more the noninnocent 41 role of Tris in the film formation. Noteworthy, Tris involvement 42 results also in a different $\mathrm{RC}$ encapsulation, i.e., a gradient 43 with a surface enrichment in RC is found when the phosphate 44 buffer is used, whereas an almost constant RC/PDA ratio with 45 a strong gradient in roughness is found when Tris buffer is 46 used. The film compositional analysis has been retrieved by 47 fitting the ellipsomteric spectra. The working assumption that 48 the film layer is a linear gradient in the refractive index was 49 used once the simple fitting model assuming a homogeneous 50 layer failed. A highly satisfactory fit was instead achieved by the 51 linear gradient model.

SEM analysis of RC-PDA films grown from DA $5 \times 10^{-3}$ M 53 on silicon substrates (see Figure S7, Supporting Informa- 54 tion) shows a continuous polymer network, embedding 55 round shaped nanostructures of $40-70 \mathrm{~nm}$, irrespectively 56 from the type of buffer used during the polymerization, in 57 agreement with AFM and ellipsometry surface analysis dis- 58 cussed above. 


\subsection{Characterization of Photoactive RC Incorporated into the PDA Film}

The film obtained by adhesion of PDA nanoaggregates on ITO is easily handled and minimal loss in encapsulated RC is found after rinsing it with deionized water. Figure 4 shows the characteristic RC pigment peaks at 1.64, 1.54, and $1.53 \mathrm{eV}(756,805$, and $867 \mathrm{~nm}$, respectively) in rinsed films.

The RCs are entrapped inside the PDA film in multiple stacked dense layers; indeed form the peak at $805 \mathrm{~nm}$ $\left(\varepsilon=288 \times 10^{-3} \mathrm{M}^{-1} \mathrm{~cm}^{-1[58]}\right)$ it is possible to infer a concentration of $\mathrm{RC} \approx 10 \times 10^{-12} \mathrm{~mol} \mathrm{~cm}{ }^{-2}$, comparable to previous data reported for densely packed RC monolayer. ${ }^{[59,60]}$ AFM and ellipsometry, indeed (see Section 2.3), show that the film deposited on ITO starting from DA $5 \times 10^{-3} \mathrm{M}$ in $\mathrm{P}_{250} \mathrm{TX}_{0.03}$ has a thickness of $20 \mathrm{~nm}$ and shows a remarkable RC occupancy that is constantly equal to $50 \%$ along the entire thickness (see Figure $3 b)$.

The RC photoactivity can be assayed measuring the absorbance changes at $865 \mathrm{~nm}$ upon single flash excitation, as detailed in Section S2 of the Supporting Information. The sudden change in the absorbance is generated by the formation of the charge separated state, directly proportional to the concentration of photoactive $\mathrm{RC}$ that disappears due to the recombination of charges with an exponential kinetics. Figure 5 shows the kinetic of the charge recombination reaction in RC-PDA films. By using the initial amplitude of the signal and the differential molar extinction coefficient $\Delta \varepsilon_{865}=105 \times 10^{-3} \mathrm{M}^{-1} \mathrm{~cm}^{-1}$, a concentration of $(11 \pm 1) \times 10^{-12} \mathrm{~mol} \mathrm{~cm}^{-2}$ photoactive RC is found, in very good agreement with that calculated by vis-NIR absorption spectroscopy $\left(10 \times 10^{-12} \mathrm{~mol} \mathrm{~cm}^{-2}\right)$. Furthermore, the kinetics of the decay of the charge separated state indicates that the loosely bound quinone is lost in the RC/PDA polymer.

The same experiment was carried in RC-PDA films polymerized in $\mathrm{T}_{250} \mathrm{TX}_{0.03}$ buffer and the resulting surface concentration was found comparable to the phosphate case and equal to $8 \times 10^{-12} \mathrm{~mol} \mathrm{~cm}^{-2}$.

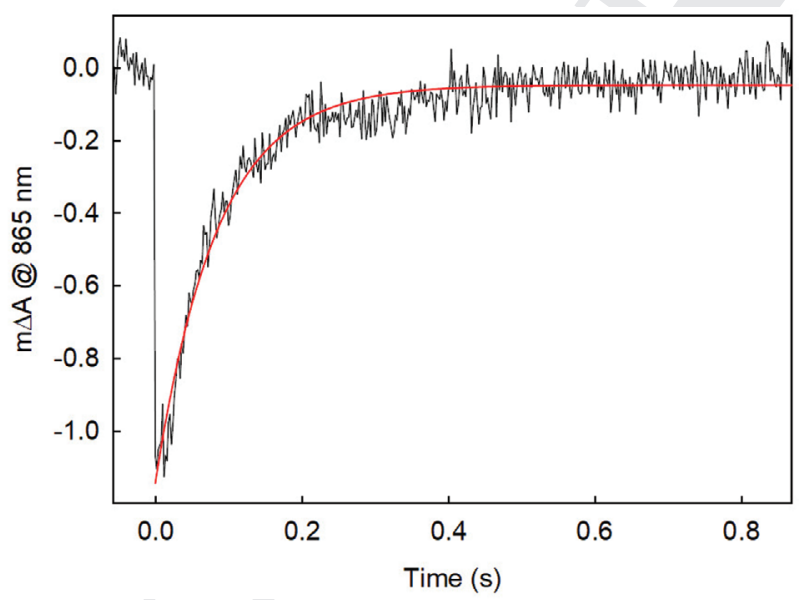

Figure 5. Absorbance change recorded at $865 \mathrm{~nm}$ of RC-PDA/ITO The signal is an average of 128 flashes. Polymerization conditions: RC $3 \times 10^{-6} \mathrm{M}$, DA $5 \times 10^{-3} \mathrm{M}$ in $\mathrm{P}_{250} \mathrm{TX}_{0.03}, \mathrm{pH} 8.0$. The decay of the charge recombination state can be fitted to a monoexponential function with amplitude $-(1.1 \pm 0.5) \mathrm{mA}$ and a kinetic constant of $k=11.9 \pm 0.1 \mathrm{~s}^{-1}$.

\subsection{Photocurrent Generation by the RC-PDA/ITO Coated Electrode}

The RC-PDA/ITO photoelectrode is assembled to generate an electric current sustained by continuous illumination by exploiting the photocycle of the reaction center; the role of the physiological external electron donor and acceptors of the photocycle (Figure 1b) can be played, respectively, by ferrocenemethanol (FcnOH) and decylubiquinone (dQ). A three electrodes photoelectrochemical cell is assembled, as detailed in the Experimental Section, using ITO slides as working electrode (WE). All experiments were performed setting the WE potential at the open circuit voltage (OCV) value of $-0.1 \mathrm{~V}$ versus $\mathrm{Ag} / \mathrm{AgCl}$ reference electrode.

Photocurrents were recorded under several conditions. A full list is given in Section S3 of the Supporting Information along with all the control experiments. All experiments are performed with a light intensity saturating for the entrapped RC.

\subsubsection{ITO Dipped in RC Suspension (RC/ITO)}

A cathodic photocurrent of $1 \mu \mathrm{A} \mathrm{cm}^{-2}$ (pink trace, Figure 6a) was recorded using WE prepared by dipping overnight an ITO slide in $3 \times 10^{-6} \mathrm{M}$ RC dissolved in $\mathrm{P}_{100} \mathrm{TX}_{0.03}$ and then gently rinsing it with deionized water (RC/ITO). This RC/ITO was immersed in a cell containing $\mathrm{FcnOH}$ and dQ in a solution buffered $\left(\mathrm{P}_{100} \mathrm{TX}_{0.03}\right)$ at $\mathrm{pH}$ 7.0. The photocurrent is stable since the photocycle rate is limited by the low RC concentration on the electrode surface and reaches a steady state condition established from the rates of diffusion of mediators from the bulk and their reactions to electrodes.

\subsubsection{RC-PDA Film on ITO (RC-PDA/ITO)}

a) RC-PDA/ITO electrode prepared in $\mathrm{P}_{250} \mathrm{TX}_{0.03}$. The electrode is immersed in a cell containing $\mathrm{FcnOH}$ and dQ in a solution buffered $\left(\mathrm{P}_{100} \mathrm{TX}_{0.03}\right)$ at $\mathrm{pH}$ 7.0. The photocurrent reaches an initial peak of $15 \mu \mathrm{A} \mathrm{cm}^{-2}$, decaying to $3-4 \mu \mathrm{A} \mathrm{cm}^{-2}$ within $10 \mathrm{~s}$ (black trace in Figure 6a). The photoresponse was found to be reproducible for at least ten cycles, after adequate dark intervals. In this WE configuration, the high initial photocurrent density arises from the high RC density inside the PDA layer. To the best of our knowledge, $15 \mu \mathrm{A} \mathrm{cm}^{-2}$ is among the highest ones reported in literature, for electrodes coated with comparable RC surface density. ${ }^{[31]}$

Unfortunately, this value decays likely because i) the RC photocycle depletes the mediators nearby the electrode at a rate higher than their diffusion rate from the solution bulk, and ii) the short circuit side reaction between $\mathrm{FnOH}^{+}$and $\mathrm{dQH}_{2}$ becomes relevant as these species accumulate in solution during the RC photocycle. ${ }^{[52,61]}$

\subsection{3. b) RC-PDA/ITO Electrode Prepared in $T_{250} T X_{0.03}$}

The use of Tris as polymerization buffer influences the photocurrents. WE obtained using phosphate generates a
1 2 3 4 5 6 7 8 9 10 11 12 13 


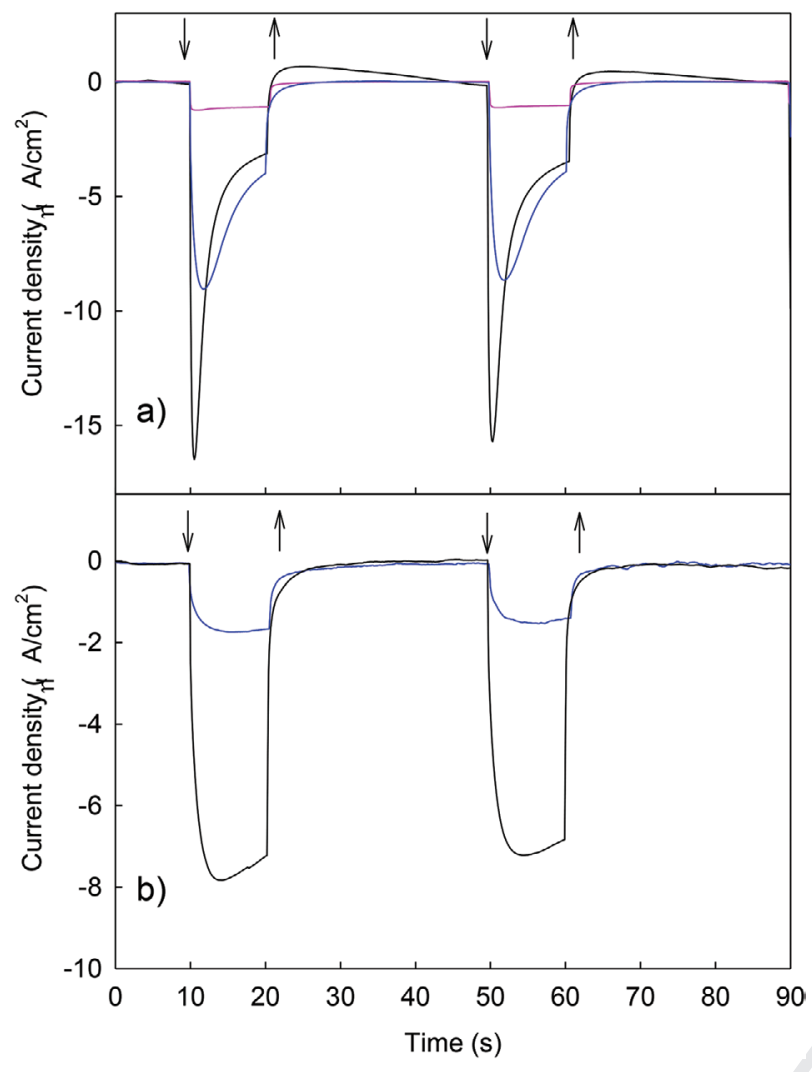

Figure 6. a) Photocurrent profiles detected in presence of mediators $\mathrm{FcnOH} 300 \times 10^{-6} \mathrm{M}$ and dQ $100 \times 10^{-6} \mathrm{M}$ using the following WEs: RC/ ITO (pink trace), RC-PDA/ITO from $\mathrm{P}_{250} \mathrm{TX}_{100}$ (black trace), and RC-PDA/ ITO from $\mathrm{T}_{250} \mathrm{TX}_{0.03}$ (blue trace). b) Photocurrent profiles detected in the presence of FeCN $10 \times 10^{-3} \mathrm{M}$ WEs of RC-PDA/ITO from $\mathrm{P}_{250} \mathrm{TX}_{100}$ (black trace) and from $\mathrm{T}_{250} \mathrm{TX}_{0.03}$ (blue trace) incorporating dQ and $\mathrm{FcnOH}$. All experiments were performed in the buffer $\mathrm{P}_{100} \mathrm{TX}_{100}$ at $\mathrm{pH}$ 7.0. Downward and upward arrows indicate light switching on and off, respectively. photocurrent almost twice as larger as WE obtained using Tris 1 (blue trace in Figure 6a). This result could be interpreted in 2 view of the ellipsometry results (Figure 3 ) showing that PDA 3 films obtained in phosphate are thinner than in Tris, while 4 containing comparable amounts of RC as inferred by photoac- 5 tivity experiments. In Tris case, the photoresponse might result 6 diminished by both the lower RC light harvesting efficiency and 7 the possibly slower mediator diffusion through the thicker PDA 8 layer to the electrode.

\subsubsection{RC-PDA Film on ITO (RC-PDA/ITO) Encapsulating Redox Mediators}

The response of the photoelectrode was improved by encap- 15 sulating the redox mediators, dQ $\left(100 \times 10^{-6} \mathrm{M}\right)$ and $\mathrm{FcnOH} 16$ $\left(300 \times 10^{-6} \mathrm{M}\right)$, added to the polymerization solution. Photo- 17 currents were recorded in presence of potassium ferrocyanide 18 $(\mathrm{FeCN}) 10 \times 10^{-3} \mathrm{M}$. Control experiments of are given in Section 19 S4 of the Supporting Information.

Stable photocurrents of 7 and $2 \mu \mathrm{A} \mathrm{cm}^{-2}$ are recorded for 21 the WE obtained in phosphate (Figure $6 \mathrm{~b}$, black trace) and in 22 Tris (Figure 6b, blue trace) buffers, respectively. As sketched in 23 Figure 7, when light activates the RC, it reduces dQ to dQH 24 withdrawing electrons from $\mathrm{FcnOH}$, whose oxidized form is 25 in turn reduced at the ITO electrode (cathodic reaction), while 26 $\mathrm{FeCN}$ donates electrons to the platinum counter electrode 27 closing the circuit (anodic reaction). The reoxidation of $\mathrm{dQH}_{2} 28$ is accomplished by oxidized $\mathrm{FeCN}$ or by the dissolved oxygen. $\quad 29$

The chronoamperometric profile obtained using RC-PDA/ 30 ITO WEs encapsulating the redox mediator and in the presence 31 of bulk-dissolved FeCN (black trace in Figure 6b) is smaller in 32 amplitude with respect to the same experiment done with bulk 33 dissolved mediators but does not show the rapid decay observed 34 using mediators in solution (black trace in Figure 6a). In the 35

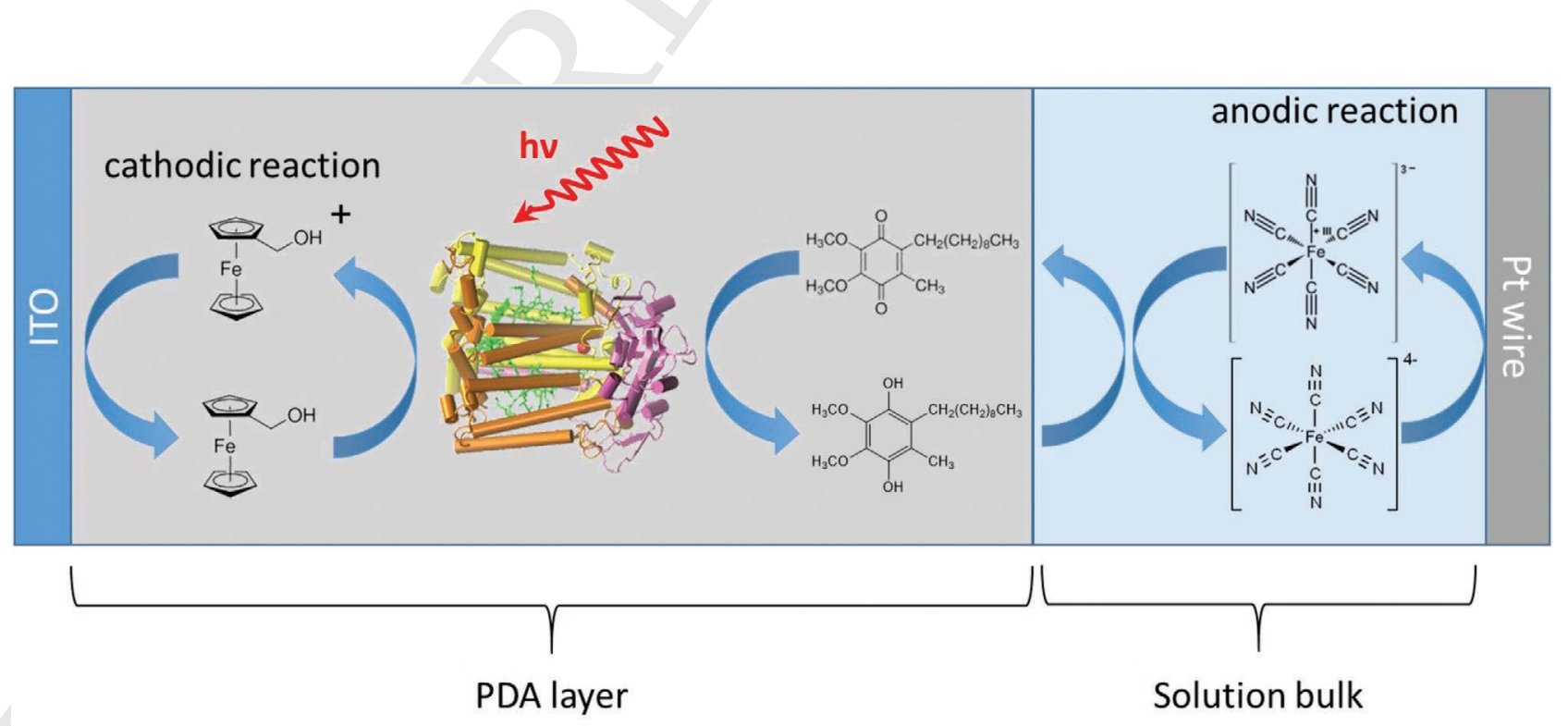

Figure 7. Scheme of the photoelectrochemical cell based on a Pt wire anode, the FeCN in $\mathrm{P}_{100} \mathrm{TX}_{0.03}$ electrolytic solution and the PDA-coated ITO WE incorporating RC, dQ and FcnOH. The reference electrode has not been depicted for simplicity. The different phases are not to scale. 
Table 1. Summary of parameters for first peak of photocurrent shown in Figure 6.

\begin{tabular}{lcc}
\hline Sample & $\begin{array}{c}\text { Peak current density } \\
{\left[\mu \mathrm{A} \mathrm{cm}^{-2}\right]}\end{array}$ & $\begin{array}{c}\text { Integral } \\
{[\mu \mathrm{C}]}\end{array}$ \\
\hline RC/ITO & -1.25 & 120 \\
RC-PDA/ITO prepared in $\mathrm{T}_{250} \mathrm{TX}_{0.03}$ & -9.10 & 650 \\
RC-PDA/ITO prepared in $\mathrm{P}_{250} \mathrm{TX}_{0.03}$ & -16.5 & 650 \\
RC-PDA/ITO encapsulating redox & -1.72 & 180 \\
mediators prepared in $\mathrm{T}_{250} \mathrm{TX}_{0.03}$ & & \\
RC-PDA/ITO encapsulating redox & -7.83 & 770 \\
mediators prepared in $\mathrm{P}_{250} \mathrm{TX}_{0.03}$ & & \\
\hline
\end{tabular}

absence of FeCN no significant photocurrent is detected, while in the case of bulk-dissolved mediators the presence of $\mathrm{FeCN}$ results is little or no change of the chronoamperometric profile.

Coincorporation of mediators in RC-PDA films mitigate the diffusion issues responsible of the spike because of i) the high local concentration of RC and mediators and their confinement in the close proximity of the electrode, and ii) the reduced short circuit side reaction rate between $\mathrm{FcnOH}^{+}$and $\mathrm{dQH}_{2}$ due to their low diffusion rate inside polymeric matrixes. ${ }^{[62]}$ This in situ polymerization produced WEs having photocurrent density that remain fairly stable up to $100 \mathrm{~s}$ of illumination (Figure S8, Supporting Information). WEs prepared from $\mathrm{T}_{250} \mathrm{TX}_{0.03}$ led to similarly stable but significantly lower photocurrents (Figure 6b blue trace).

A summary of all detected photocurrents parameters is presented in Table 1. Noteworthy, the highest total charge (integral) is that obtained with the RC-PDA/ITO WE encapsulating redox mediators prepared in $\mathrm{P}_{250} \mathrm{TX}_{0.03}$.

\subsection{Internal and External Quantum Efficiencies of WEs}

The internal quantum efficiency, i.e., the number of electrons pumped in the circuit divided by the number of absorbed photons, calculated according to Kamran et al., ${ }^{[31]}$ for the RC-PDA/ ITO and RC-PDA/ITO + mediators WEs prepared in phosphate were found 39\% (at the peak intensity) and 21\%, respectively. The IQE obtained in RC-PDA/ITO is comparable to that reported in the literature (32\%) for a uniformly oriented RC/ LH1 film deposited by more sophisticated LB technique onto an electrode surface. ${ }^{[31]}$

The photocurrents obtained from RC-PDA/ITO + mediators WEs were also measured in the wavelength range 580-910 nm, using a set of $10 \mathrm{~nm}$ bandpass interferential filters. The photoenzyme action spectrum is shown in Figure 8 were the external quantum efficiency (EQE, i.e., the number of electrons pumped in the circuit divided by the number of incident photons) is plotted versus the excitation wavelengths. The data show a good correspondence with the optical spectrum of the RC.

The structural integrity of the RC in RC-PDA/ITO working electrodes was also monitored in time (see Section S6 of the Supporting Information). The photoresponse of the protein was recorded during a time interval of 9 days showing that the presence of PDA does not protect the RC from photodegradation, while it does have a protective role against denaturation.

\section{Conclusions}

This work presents a simple and mild procedure for assembling polydopamine films deposited onto ITO. The procedure is biocompatible and allows the encapsulation of fully functional photosynthetic reaction center.

The assembly formed by the photoenzyme encapsulated in the polydopamine film deposited on ITO is a well-performing photoelectrode that, with the use of the opportune redox mediator, has been successfully used in photoelectrochemical cells. The high density packing of the protein within the film produces a remarkably high, but unstable, photocurrent when the mediators are freely diffusing in the electrolytic solution. A lower but very stable photocurrent having an internal quantum efficiency of $21 \%$ is obtained when mediators are encapsulated with the reaction center in the film.

\section{Experimental Section}

Chemicals: All chemicals were purchased at the highest available purity degree and were used without further purification. The reagent grade salts for the phosphate buffer solutions, dQ, FcnOH, Triton X-100 (TX), FeCN, tris-(hydroxymethyl)-aminomethane (Tris), fluorescein isothiocyanate (FITC), and dopamine hydrochloride were purchased from Sigma. Lauryl dimethyl amino $\mathrm{N}$-oxide (LDAO) was from Fluka. All aqueous solutions were prepared using water obtained by Milli-Q Gradient A-10 system (Millipore, $18.2 \mathrm{M} \Omega \mathrm{cm}$, organic carbon content $\leq 4 \mu \mathrm{g} \mathrm{L^{-1 }}$ ). ITO glass slides of $15 \times 9 \times 0.7 \mathrm{~mm}^{3}$ with a surface resistivity of $\approx 10 \Omega \mathrm{sq}^{-1}$ and a transmittance $>85 \%$ were washed in $5 \%$ Hellmanex solution, rinsed with bidistilled water and finally washed in methanol.

$R C$ Protein Purification: $R$. sphaeroides R26 was grown photoheterothrophically under anaerobic conditions in medium supplemented with potassium succinate. ${ }^{[63]} \mathrm{RCs}$ were isolated as previously described. ${ }^{[64]}$ Protein purity was checked using the absorbance ratio $A_{280} / A_{802}$, which was kept below 1.4, while structural integrity was established by the ratio $A_{760} / A_{802}$ which is equal to 1 for pure and intact RC proteins. ${ }^{[58]} \mathrm{RCs}$ were concentrated to $\approx 50 \times 10^{-6} \mathrm{M}$ by centrifugation with Amicon Centricon-30, dialyzed against a buffered composed by tris(hydroxymethyl)aminomethane (Tris) $15 \times 10^{-3} \mathrm{M}, \mathrm{N}, \mathrm{N}$-Dimethyldodecylamine $\mathrm{N}$-oxide (LDAO) $0.025 \%$ $\mathrm{v}: \mathrm{v}$, Ethylenediaminetetraacetic acid $1 \times 10^{-3} \mathrm{M}, \mathrm{pH} 8.0\left(\mathrm{~T}_{15} \mathrm{~L}_{0.025} \mathrm{E}_{1}\right)$,

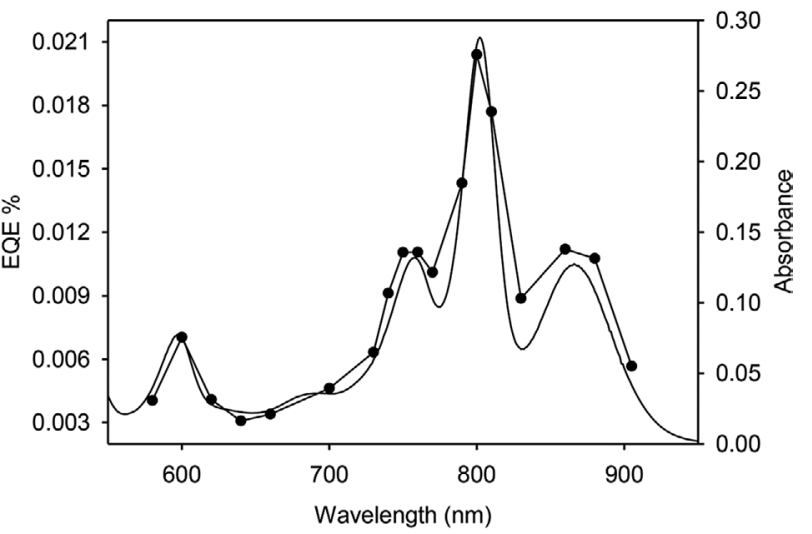

Figure 8. Absorption RC spectrum (black continuous line) superimposed to the corresponding action spectrum (circles) of a RC-PDA/ITO + mediators working electrode obtained in $\mathrm{P}_{250} \mathrm{TX}_{0.03}$. The photoelectrochemical cell is described in Figure 7. 

spectrophotometrically using $\varepsilon_{802}=288 \times 10^{-3} \mathrm{M}^{-1} \mathrm{~cm}^{-7}$. ${ }^{65]}$

$R C$ Incorporation in Suspended PDA Nanoaggregates: The incorporation of the RC into the PDA nanoaggregates was performed preparing a mixture of $3 \times 10^{-6} \mathrm{M}$ protein, $2-25 \times 10^{-3} \mathrm{M}$ DA either in $3 \mathrm{~mL}$ phosphate $250 \times 10^{-3} \mathrm{M}, \mathrm{TX}-1000.03 \% \mathrm{pH} 8.0\left(\mathrm{P}_{250} \mathrm{TX}_{0.03}\right.$ buffer $)$ or Tris $250 \times 10^{-3} \mathrm{M}, \mathrm{TX}-1000.03 \% \mathrm{pH} 8.0\left(\mathrm{~T}_{250} \mathrm{TX}_{0.03}\right.$ buffer). The suspension was stirred overnight at room temperature in an open vessel to allow the oxygen-mediated polymerization favored by the alkaline condition. During the growth of the colloidal polymeric aggregates, the RCs are captured and entrapped within the nanostructures. The suspension was finally ultracentrifuged at $33000 \times \mathrm{g}$ for $1 \mathrm{~h}$ at $4{ }^{\circ} \mathrm{C}$. The sedimented nanoaggregates (resuspended in the same buffer) and supernatants were analyzed spectrophotometrically to check the protein content.

RC Incorporation in ITO-Anchored PDA Nanoaggregates: For this purpose, glass slides $(1.2 \times 1.0 \mathrm{~cm})$ with the ITO face upward were placed into open vessels containing typically $3 \times 10^{-6} \mathrm{M} \mathrm{RC}, 2-25 \times 10^{-3} \mathrm{M} \mathrm{DA}$ in $3 \mathrm{~mL} \mathrm{P}_{250} \mathrm{TX}_{0.03}$ or $\mathrm{T}_{250} \mathrm{TX}_{0.03}$ buffers. The suspension was analogously stirred overnight at room temperature to allow the oxygen-mediated polymerization (Figure 2a). When needed, dQ $100 \times 10^{-6} \mathrm{M}$ and/or $\mathrm{FcnOH} 300 \times 10^{-6} \mathrm{M}$ were also added to the starting suspension. The glass slides were finally thoroughly rinsed with deionized water and used for further experiments.

Steady State and Transient Optical Spectroscopy: Steady state optical spectra were recorded by a Cary 5000 (Agilent) UV-visible-NIR spectrophotometer.

Transient absorption experiments were performed using a kinetic spectrometer of local design, described elsewhere. ${ }^{[66]}$ The excitation of the sample is provided by a Hamamatsu 15 W L4634-01 xenon lamp for single flash excitation.

Transient absorption experiments on RC-PDA films were performed placing the coated ITO slide in the sample holder of the kinetic spectrometer with the film facing toward the exciting flash light at $45^{\circ}$ tilting with respect to the measuring beam that is, in turn, orthogonal to the flash light.

Atomic Force Microscopy Measurements: Measurements of noncontact intermittent mode AFM were performed using an Autoprobe CP Thermomicroscope to determine the PDA particle diameter and to investigate the film morphology and aggregation state of RC-PDA films as a function of DA concentration and used buffer (phosphate vs Tris). A sharp conical tip with a radius of curvature $<10 \mathrm{~nm}$ and an amplitude of vibration of $80 \mathrm{kHz}$ (dLever series probes) mounted on a p-type doped Si cantilever was used.

Spectroscopic Ellipsometry Measurements: Optical characterization of films of RC, PDA, and RC-PDA was performed by spectroscopic ellipsometry (SE). SE spectra of the pseudocomplex refractive index $\langle N\rangle=(n+i k)$ (where $n$ is the real refractive index and $k$ is the extinction coefficient) were measured in the 1.0-6.5 eV (1024-190 nm) range with a resolution of $0.05 \mathrm{eV}$ at an incidence angle of $70^{\circ}$ using a phasemodulated ellipsometer (UVISEL, Jobin Yvon).

To derive the film thickness and spectral dispersion of $n$ and $k$ from the measured SE spectra of the RC and PDA films polymerized on glass slides, a simple substrate/film/air model fit analysis was used. A single Lorentzian oscillator model was used to model the PDA layer, whereas five Lorentzian oscillators described the main optical transitions of the RC layer obtained drop casting $1 \mu \mathrm{L}$ of a concentrated suspension of RC $\left(55 \times 10^{-6} \mathrm{M}\right)$ on a $2 \times 2 \mathrm{~cm}$ glass slide (RC surface density $14 \times 10^{-12} \mathrm{~mol} \mathrm{~cm}^{-2}$ ) and dried under nitrogen flux. From the modeling, RC was estimated, a thickness of $78 \pm 15 \AA$ that is consistent with the RC dimension ${ }^{[67]}$ and hence a deposited 1 monolayer of RC.

Once determined the optical function of the RC and PDA, the RC-PDA films were modeled using Bruggeman effective medium approximation. Figure 9 shows the spectra of the refractive index, $n$, and extinction coefficient, $k$, of PDA and RC layers. For PDA, values of the refractive index in the range $1.45-1.47$ at $633 \mathrm{~nm}$ are reported in literature, ${ }^{[68,69]}$ which are in good agreement with the data, as indicated by the dots in Figure 9a. Figure 9b shows the spectra of the refractive index and extinction coefficient derived for the RC film. For comparison, also the

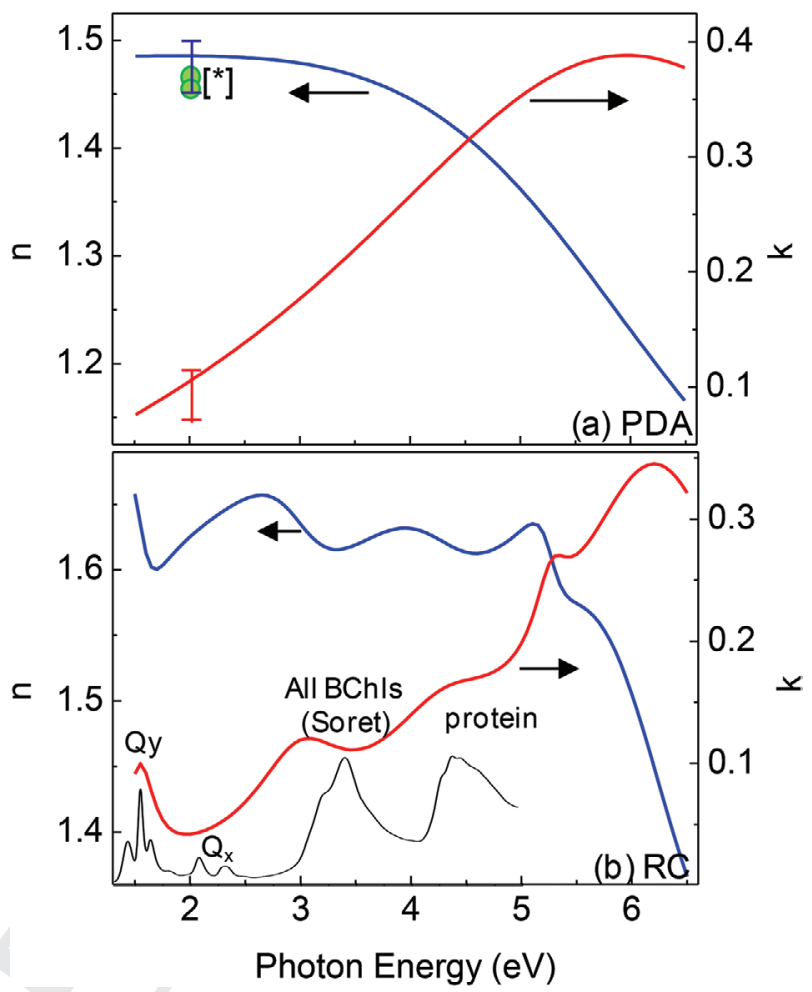

1

2

3

4

5

6

7

8

10

11

12

13

14

15

16

17

18

19

20

21

22

23

24

25

26

Figure 9. Optical spectra of the refractive index, $n$, and extinction coefficient, $k$, of the PDA a) and RC b) layers, respectively. In a) some values of the refractive index at $633 \mathrm{~nm}$ from literature are indicated by the green dots from refs., ${ }^{[68,71,72]}$ while the bars represent the variability of $n$ and $k$ values obtained on PDA films obtained at various concentration of PDA. In c) the absorption spectrum of the RC in suspension is also shown for comparison (black curve); for the RC in suspension the axis absorbance in relative unit is not shown; the spectrum is for the qualitative comparison of the bands.

absorbance spectrum of the RC film is reported showing the protein absorbance at $\approx 4.4 \mathrm{eV}(280 \mathrm{~nm})$ and three sets of bands of the Soret (3-4 eV, 413-310 nm), $Q_{x}(2-2.5 \mathrm{eV}, 620-500 \mathrm{~nm})$, and $\mathrm{Q}_{y}(1.3-1.9 \mathrm{eV}$, 950-650 nm) due to BChl and BPhe cofactors.

From the ellipsometric analysis, the main absorptions were found due to the protein and cofactors bands redshifted to $3.1 \mathrm{eV}$ (400 instead of $366 \mathrm{~nm}$ ) and $4.3 \mathrm{eV}$ (288 instead of $280 \mathrm{~nm}$ ) due to intermolecular electronic coupling in the solid state compared to suspension; the redshift at $1.52 \mathrm{eV}(816 \mathrm{~nm}$ instead of 802$)$ in the NIR region is rather inaccurate because the resolution of $0.05 \mathrm{eV}$ corresponds to $25 \mathrm{~nm}$ in this wavelength range; in the UV-region, additional absorption peaks at $5.35 \mathrm{eV}(232 \mathrm{~nm})$ and $6.2 \mathrm{eV}(200 \mathrm{~nm})$ due to $\pi-\pi^{*}$ excitation of benzene-units ${ }^{[0]}$ are also seen. Those optical transitions of the RC, together with that at $1.52 \mathrm{eV}$ can be used further on as the optical direct signature of the effective inclusion of RC in the RC-PDA films.

Electrochemical Measurements: Photoelectrochemical measurements were conducted at room temperature in a three-electrode cell, adapted to a plastic cuvette $\left(1 \times 1 \mathrm{~cm}^{2}\right.$ base and $1.5 \mathrm{~cm}$ height $)$ by using an Autolab potentiostat PGSTAT 10. A micro $\mathrm{Ag} / \mathrm{AgCl}$ electrode was used as reference and a platinum wire as counter-electrode. The RC-PDA covered ITO was the WE and $1 \mathrm{~mL}$ of phosphate $100 \times 10^{-3} \mathrm{M}, \mathrm{TX}-1000.03 \% \mathrm{pH} 7.0$ $\left(\mathrm{P}_{100} \mathrm{TX}_{0.03}\right)$ water solution was the support electrolyte. The electroactive WE area, i.e., the portion of the RC/PDA film immersed in solution, was $9 \times 10 \mathrm{~mm}^{2}$. FcnOH $300 \times 10^{-6} \mathrm{M}$ as electron donor, dQ $100 \times 10^{-6} \mathrm{M}$ as electron acceptor and $\mathrm{FeCN} 10 \times 10^{-3} \mathrm{M}$ as electrochemical mediator were added in solution when needed. A bias of $-0.1 \mathrm{~V}$ (corresponding to the OCV of the cell in the dark) was applied between the reference and 
the working electrodes. For the photocurrent generation, the WE, with the film-covered side facing toward the light source, was illuminated with a $2.6 \mathrm{~W}$ LED emitting at $865 \mathrm{~nm}$ (corresponding to one of the three major RC peaks in the NIR) with an irradiance of $25 \mathrm{~mW} \mathrm{~cm}$, providing $1.1 \times 10^{17}$ photons $\mathrm{s}^{-1} \mathrm{~cm}^{-2}$. Light/dark cycles were performed using $10 \mathrm{~s}$ for light excitation and $40 \mathrm{~s}$ for dark relaxation.

Scanning Electron Microscopy Characterization: For this analysis, two silicon wafers were placed in open vessels containing DA $5 \times 10^{-3} \mathrm{M}$ and RC $3 \times 10^{-6} \mathrm{M}$ in either $\mathrm{P}_{250} \mathrm{TX}_{0.03}$ or $\mathrm{T}_{250} \mathrm{TX}_{0.03} \mathrm{pH}$ 8.0. The suspensions were stirred overnight at room temperature allowing the polymerization. Films were washed thoroughly with deionized water to remove salts. A Zeiss Sigma (Oberkochen, Germany) field emission and scanning electron microscope operating in the range of $0.5-20 \mathrm{kV}$ and equipped with a secondary electron detector and back diffusion was used for the characterization. Low accelerating voltage set to $2 \mathrm{keV}$ was exploited. Samples were mounted onto double sided carbon tape and grounded with silver paste.

Fluorescence Microscopy: Observations were performed by an epifluorescence microscope (Axiomat, Zeiss, Oberkochen, Germany) using FITC excitation filter $\left(\lambda_{\mathrm{ex}}=467-498 \mathrm{~nm}, \lambda_{\mathrm{em}}=513-556 \mathrm{~nm}\right)$. Fluorescence images were captured with a Nikon DSVil digital camera (Nikon Instruments, Europe BV, Kingston, Surrey, England) and NIS Elements BR 3.22 imaging software (Nikon Instruments, Europe BV, Kingston, Surrey, England). Samples were observed at $20 \times$ and $50 \times$ magnifications.

\section{Supporting Information}

Supporting Information is available from the Wiley Online Library or from the author.

\section{Acknowledgements}

The authors thank Steven Vertueux for help in some electrochemical experiments. This work was financially supported by Ministero dell'Istruzione, dell'Università e della Ricerca (MIUR), Research Project of National Interest (prot. 2010C4R8M8); MIUR and DiTECH (PON 02_00563_3316357 Molecular Nanotechnology for Health and Environment MAAT); Apulia Region funded Project RELA-VALBIOR, Network of Laboratories for Scientific Research (Italy); FET open EU project 800926 - HyPhOE - Hybrid Electronics based on Photosynthetic Organisms.

\section{Conflict of Interest}

The authors declare no conflict of interest.

\section{Keywords}

biophotovoltaics, photocurrents, photosynthetic bacteria, polydopamine, reaction centers

Received: February 7, 2020 Revised: April 18, 2020 Published online:

[1] A. Operamolla, R. Ragni, F. Milano, R. R. Tangorra, A. Antonucci, A. Agostiano, M. Trotta, G. M. Farinola, J. Mater. Chem. C 2015, 3, 6471.

[2] F. Milano, A. Punzi, R. Ragni, M. Trotta, G. M. Farinola, Adv. Funct. Mater. 2019, 29, 1970141.
[3] S. K. Ravi, S. C. Tan, Energy Environ. Sci. 2015, 8, 2551.

[4] W. W. Fischer, J. Hemp, J. E. Johnson, Annu. Rev. Earth Planet. Sci. 2 2016, 44, 647.

[5] M. M. Najafpour, H. J. M. Hou, S. I. Allakhverdiev, in Photosynthesis: Structures, Mechanisms, and Applications (Eds: H. J. M. Hou, M. M. Najafpour, G. F. Moore, S. I. Allakhverdiev), Springer, Cham, Switzerland 2017.

[6] A. C. Gonzalez-Aravena, K. Yunus, L. Zhang, B. Norling, A. C. Fisher, RSC Adv. 2018, 8, 20263.

[7] A. Agostiano, F. Milano, M. Trotta, Eur. J. Biochem. 1999, 262, 358.

[8] K. Hajdu, T. Szabó, A. E. Sarrai, L. Rinyu, L. Nagy, Int. J. Photoenergy 2017, 2017, 9128291.

[9] E. Espiritu, K. D. Chamberlain, J. C. Williams, J. P. Allen, Photosynth. Res. 2019, 143, 129.

[10] G. Feher, J. P. Allen, M. Y. Okamura, D. C. Rees, Nature 1989, 339, 111

[11] F. Milano, R. R. Tangorra, A. Agostiano, L. Giotta, V. De Leo F. Ciriaco, M. Trotta, MRS Adv. 2018, 3, 1497.

[12] C. A. Wraight, R. K. Clayton, Biochim. Biophys. Acta 1974, 333, 246.

[13] J. Koepke, E.-M. Krammer, A. R. Klingen, P. Sebban, G. M. Ullmann, G. Fritzsch, J. Mol. Biol. 2007, 371, 396.

[14] J. P. Allen, G. Feher, T. O. Yeates, H. Komiya, D. C. Rees, Proc. Natl. Acad. Sci. USA 1988, 85, 8487.

[15] J. P. Allen, G. Feher, T. O. Yeates, H. Komiya, D. C. Rees, Proc. Natl. Acad. Sci. USA 1987, 84, 6162

[16] J. P. Allen, G. Feher, T. O. Yeates, H. Komiya, D. C. Rees, Proc. Natl. Acad. Sci. USA 1987, 84, 5730.

[17] L. Gerencser, P. Maroti, Biochemistry 2006, 45, 5650.

[18] A. Mallardi, G. Palazzo, G. Venturoli, J. Phys. Chem. B 1997, 101, 7850.

[19] F. Milano, F. Italiano, A. Agostiano, M. Trotta, Photosynth. Res. 2009 100, 107.

[20] E. Altamura, F. Milano, M. Trotta, P. Stano, F. Mavelli, Advances in Bionanomaterials, Springer, Cham, Switzerland 2018, p. 97.

[21] E. Altamura, R. Fiorentino, F. Milano, M. Trotta, G. Palazzo, P. Stano, F. Mavelli, Biophys. Chem. 2017, 229, 46

[22] E. Altamura, F. Milano, R. R. Tangorra, M. Trotta, O. Hassan Omar P. Stano, F. Mavelli, Proc. Natl. Acad. Sci. USA 2017, 114, 3837.

[23] F. Milano, L. Giotta, M. R. Guascito, A. Agostiano, S. Sblendorio, L. Valli, F. M. Perna, L. Cicco, M. Trotta, V. Capriati, ACS Sustainable Chem. Eng. 2017, 5, 7768.

[24] R. R. Tangorra, A. Operamolla, F. Milano, O. Hassan Omar, J. Henrard, R. Comparelli, F. Italiano, A. Agostiano, V. De Leo, R. Marotta, A. Falqui, G. M. Farinola, M. Trotta, Photochem. Photobiol. Sci. 2015, 14, 1844.

[25] Y. Kim, S. A. Shin, J. Lee, K. D. Yang, K. T. Nam, Nanotechnology 2014, 25, 342001.

[26] J. Zhao, B. Liu, Y. Zou, C. Xu, J. Kong, Electrochim. Acta 2002, 47, 2013.

[27] I. Oda, M. Iwaki, D. Fujita, Y. Tsutsui, S. Ishizaka, M. Dewa, M. Nango, T. Kajino, Y. Fukushima, S. Itoh, Langmuir 2010, 26, 13399.

[28] K. Hajdu, C. Gergely, M. Martin, T. Cloitre, L. Zimanyi, K. Tenger, P. Khoroshyy, G. Palestino, V. Agarwal, K. Hernadi, Z. Nemeth L. Nagy, Langmuir 2012, 28, 11866.

[29] M. Chatzipetrou, F. Milano, L. Giotta, D. Chirizzi, M. Trotta M. Massaouti, M. R. Guascito, I. Zergioti, Electrochem. Commun. 2016, 64, 46.

[30] M. Kamran, V. M. Friebe, J. D. Delgado, T. J. Aartsma, R. N. Frese, M. R. Jones, Nat. Commun. 2015, 6, 6530 .

[31] M. Kamran, J. D. Delgado, V. Friebe, T. J. Aartsma, R. N. Frese, Biomacromolecules 2014, 15, 2833.

[32] S. A. Trammell, L. Wang, J. M. Zullo, R. Shashidhar, N. Lebedev, Biosens. Bioelectron. 2004, 19, 1649.

[33] M. Di Lauro, S. la Gatta, C. A. Bortolotti, V. Beni, V. Parkula, S. Drakopoulou, M. Giordani, M. Berto, F. Milano, T. Cramer, M. Murgia, A. Agostiano, G. M. Farinola, M. Trotta, F. Biscarini, Adv. Electron. Mater. 2020, 6, 1900888 
[34] H. Lee, S. M. Dellatore, W. M. Miller, P. B. Messersmith, Science 2007, 318, 426.

[35] H. Lee, N. F. Scherer, P. B. Messersmith, Proc. Natl. Acad. Sci. USA 2006, 103, 12999.

[36] M. Sureshkumar, P.-N. Lee, C.-K. Lee, J. Mater. Chem. 2011, 21, 12316.

[37] Q. Wei, F. Zhang, J. Li, B. Li, C. Zhao, Polym. Chem. 2010, 1, 1430.

[38] Q. Ye, F. Zhou, W. Liu, Chem. Soc. Rev. 2011, 40, 4244.

[39] F. Bernsmann, A. Ponche, C. Ringwald, J. Hemmerlé, J. Raya, B. Bechinger, J. C. Voegel, P. Schaaf, V. Ball, J. Phys. Chem. C 2009, $113,8234$.

[40] J. J. Wilker, Science 2015, 349, 582.

[41] Y. H. Ding, M. Floren, W. Tan, Biosurf. Biotribol. 2016, 2, 121.

[42] C. Zhang, L. Gong, L. Xiang, Y. Du, W. Hu, H. Zeng, Z.-K. Xu, ACS Appl. Mater. Interfaces 2017, 9, 30943.

[43] M. Abbas, F. D'Amico, L. Morresi, N. Pinto, M. Ficcadenti, R. Natali, L. Ottaviano, M. Passacantando, M. Cuccioloni, M. Angeletti, R. Gunnella, Eur. Phys. J. E: Soft Matter Biol. Phys. 2009, 28, 285.

[44] H. Coskun, A. Aljabour, L. Uiberlacker, M. Strobel, S. Hild, C. Cobet, D. Farka, P. Stadler, N. S. Sariciftci, Thin Solid Films 2018, 645, 320.

[45] H. J. Nam, J. Cha, S. H. Lee, W. J. Yoo, D. Y. Jung, Chem. Commun. 2014, 50, 1458.

[46] M. Ambrico, F. Ambrico Paolo, A. Cardone, T. Ligonzo, R. Cicco Stefania, D. Mundo Rosa, V. Augelli, M. Farinola Gianluca, Adv. Mater. 2011, 23, 3332.

[47] M. Ambrico, A. Cardone, T. Ligonzo, V. Augelli, P. F. Ambrico, S. Cicco, G. M. Farinola, M. Filannino, G. Perna, V. Capozzi, Org. Electron. 2010, 11, 1809.

[48] H. Lee, J. Rho, B. Messersmith Phillip, Adv. Mater. 2009, 21, 431.

[49] L. C. Almeida, R. D. Correia, A. Marta, G. Squillaci, A. Morana, F. La Cara, J. P. Correia, A. S. Viana, Appl. Surf. Sci. 2019, 480, 979.

[50] L. Zhang, J. Shi, Z. Jiang, Y. Jiang, S. Qiao, J. Li, R. Wang, R. Meng, Y. Zhu, Y. Zheng, Green Chem. 2011, 13, 300.

[51] M. Mohammad, A. Razmjou, K. Liang, M. Asadnia, V. Chen, ACS Appl. Mater. Interfaces 2019, 11, 1807.

[52] R. Caterino, R. Csiki, A. Lyuleeva, J. Pfisterer, M. Wiesinger, S. D. Janssens, K. Haenen, A. Cattani-Scholz, M. Stutzmann, J. A. Garrido, ACS Appl. Mater. Interfaces 2015, 7, 8099.
[53] S. Hong, Y. S. Na, S. Choi, I. T. Song, W. Y. Kim, H. Lee, Adv. Funct. 1 Mater. 2012, 22, 4711.

[54] J. Liebscher, R. Mrowczynski, H. A. Scheidt, C. Filip, N. D. Hadade, R. Turcu, A. Bende, S. Beck, Langmuir 2013, 29, 10539.

[55] N. F. Della Vecchia, A. Luchini, A. Napolitano, G. D'Errico, 5 G. Vitiello, N. Szekely, M. d'Ischia, L. Paduano, Langmuir 2014, 30, 9811.

[56] Y. Liu, K. Ai, L. Lu, Chem. Rev. 2014, 114, 5057.

[57] Q. Lyu, N. Hsueh, C. L. L. Chai, Langmuir 2019, 35, 5191.

[58] G. Feher, Photochem. Photobiol. 1971, 14, 373.

[59] E. Katz, J. Electroanal. Chem. 1994, 365, 157.

[60] R. R. Tangorra, A. Antonucci, F. Milano, A. Operamolla, F. Italiano, 11 R. Ragni, O. Hassan Omar, P. Salice, S. Silvestrini, E. Menna, 12 M. Maggini, A. Agostiano, M. Trotta, G. M. Farinola, MRS Online 13 Proc. Libr. 2015, 1717.

[61] F. Ciriaco, R. R. Tangorra, A. Antonucci, L. Giotta, A. Agostiano, 15 M. Trotta, F. Milano, Eur. Biophys. J. 2015, 44, 183.

[62] D. Buesen, T. Hoefer, H. Zhang, N. Plumere, Faraday Discuss. 2019, $215,39$.

[63] A. Buccolieri, F. Italiano, A. Dell'Atti, G. Buccolieri, L. Giotta, 18 A. Agostiano, F. Milano, M. Trotta, Anal. Chim. 2006, 96, 195.

[64] R. A. Isaacson, F. Lendzian, E. C. Abresch, W. Lubitz, G. Feher, Bio- 20 phys. J. 1995, 69, 311.

[65] S. C. Straley, W. W. Parson, D. C. Mauzerall, R. K. Clayton, Biochim. 22 Biophys. Acta 1973, 305, 597.

[66] O. Hassan Omar, S. la Gatta, R. R. Tangorra, F. Milano, R. Ragni, 23 A. Operamolla, R. Argazzi, C. Chiorboli, A. Agostiano, M. Trotta, G. 25 M. Farinola, Bioconjugate Chem. 2016, 27, 1614.

[67] M. R. Jones, Biochem. Soc. Trans. 2009, 37, 400.

[68] S. Nirasay, A. Badia, G. Leclair, J. Claverie, I. Marcotte, Materials 27 2012, 5, 2621.

[69] F. Bernsmann, L. Richert, B. Senger, P. Lavalle, J. C. Voegel, 29 P. Schaaf, V. Ball, Soft Matter 2008, 4, 1621.

[70] J. M. Antosiewicz, D. Shugar, Biophys. Rev. 2016, 8, 151.

[71] J. Jiang, Z Zhu, L. Zhu, B. Zhu, Y. Xu, Langmuir 2011, 27, 14180.

[72] F. Bernsmann, O. Ersen, J. C. Voegel, E. Jan, N. A. Kotov, V. Ball, 33 ChemPhysChem 2010, 11, 3299. 